\title{
The debate over health care reform: Houston, we have a problem
}

$T$ he political debate over health care reform will reach a tipping point early this fall. No one knows for sure what will happen. All summer we have seen a complicated subject confuse politicians, pundits, health care planners, employers, and the public. At this point one might ask, what problem are we trying to solve?

My answer to this question comes in two parts: one is reducing out-year costs for health care by bending the curve on incremental growth, and the other is enacting insurance reform to provide universal coverage and portability regardless of preexisting conditions. Changing one part has weighty consequences for the other, and so my thesis for discussion in this JCI forum is quite simple: affording insurance reform is not possible without cultural change. To pay for insurance reform, we must either accept real reductions in health care costs or be willing to pay higher taxes or higher copayments for low-value clinical services, or some combination of all three.

In truth, solutions to health care reform are always cultural and must be cautiously incremental for one important reason: health care delivery at the moment is the economy (1). At $16 \%$ of gross national product, in spite of wide recession, the health care sector still provides most of our current job growth.
Whether it is provider reimbursement, general labor costs for clinical care, medicinal or device manufacturing, facilities construction, insurance administration, information technology, or nursing home and hospice expansion, there are real incomes at stake. The middle of a recession is probably the worst time to fix something this big.

De Tocqueville, on his visit to the United States in the 1830s, observed that Americans are uniquely fixated on their sense of well-being, and Paul Starr has written there is no better example than our concern for better health (2); it is ineluctably part of our culture. While doctor-patient relationships are still the focal point of American medicine, someone else pays for them today, and this is why physicians face new, sobering demands for cost containment. As one example, at least 27 percent of health care costs are created in the last year of patients' lives (3), a percentage that has fluctuated little over time. One obvious solution would be expansion of the hospice movement as an alternative for cost-sensitive, high-quality, end-of-life care (4), but even this has been contentious. For cultural or religious reasons, the profession and public are unable to face this choice in a forthright, sensitive manner without disintegrating into hyperbolic rhetoric.

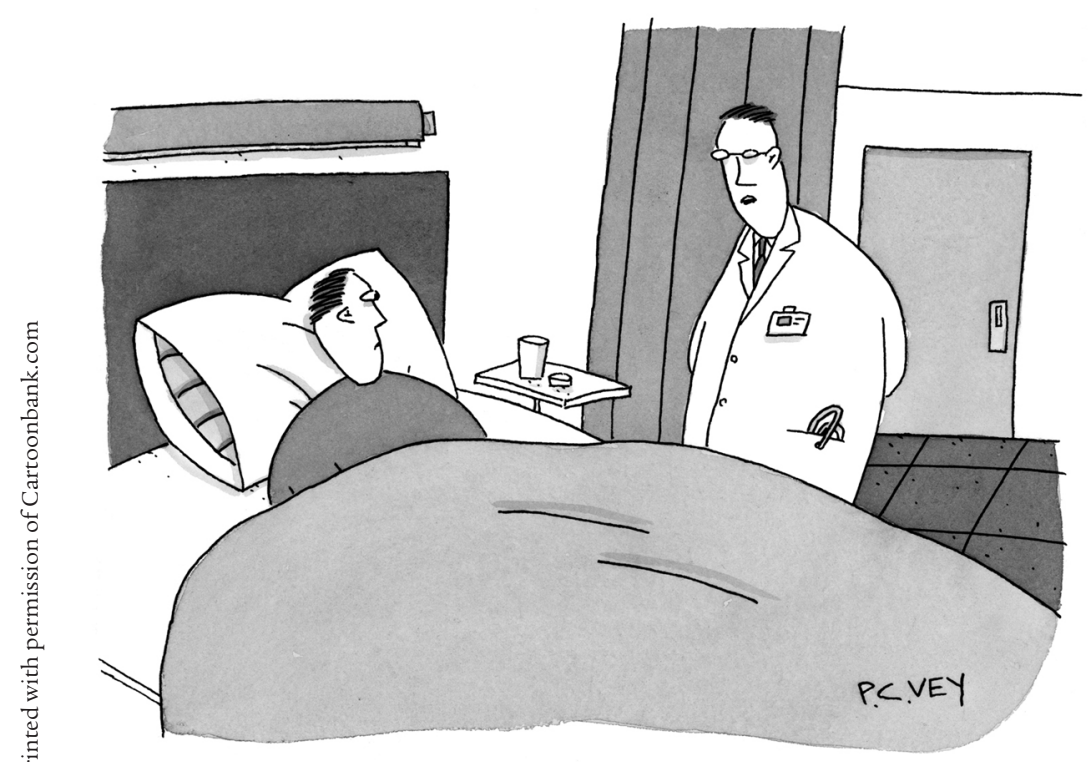

"In the future, everybody will have fifteen minutes of health-care coverage."
There probably is enough money in our present health care system to enact insurance reform without new taxes if we were more careful with our clinical and administrative resources. The historical fragmentation of the health care sector, however, requires large numbers of small pieces to reassemble for this single purpose. Such a gathering will likely raise the false alarm of rationing and undermine serious discussion about something physicians can do right now, namely, reducing the variability in practice costs among doctors treating similar patients $(5,6)$. Attention to minimizing this variability is not rationing and has tremendous possibility for real savings. Reducing the cost of health care is also complicated by various motivations. The free market profit motives in health care relationships would have to change, and physicians would have to live with more clinical uncertainty - not every question a doctor could ask need be answered with a test (5). Yes, overtesting or overtreating is a hedge against malpractice suits, but absent that, many physicians today feel no additional responsibly for cost-effectiveness. This indifference leads to thoughtless application of expensive halfway technologies in the setting of minor illness or futility (1). Physicians today increasingly find it difficult to do the right thing and only the right thing for their patients.

It is not surprising that per capita costs for health care in the United States are twice those in other developed countries (7). One reason is salaries across the entire health care sector have grown large under the guiding influence of free market health insurance. Providers use historically generous reimbursement dollars wrestled away from competing insurance plans to stimulate the growth of other goods and services needed for clinical practice. Robust insurance reimbursement over the last 50 years also greatly benefited physicians by consolidating their professional authority and status as decision makers (2). Together these relationships drive capital investment to support demand for more modern facilities, imaging, drugs, and devices - all of which we need for the right patient.

The other reason we have high per capita costs is the emergence of competitive health plans in our free market culture: their goals 


\section{The physician's voice}

At least 27 percent of health care costs are

created in the last year of patients' lives, a

percentage that has fluctuated little over time.

One obvious solution would be expansion of

the hospice movement as an alternative for

cost-sensitive, high-quality, end-of-life care,

but even this has been contentious.

are more than just paying medical bills - they also compete among themselves and between employers and providers to make profits; for its scale, this is uniquely American (2). Outside the United States, non-free market insurance plans and other social safety net programs hold down the rate of rising health care costs. In Japan you can see a doctor at little expense or get an MRI for $\$ 98$ (8), but what T.R. Reid doesn't say in his recent article is that costs are also lower in Japan because health care salaries are truly dreadful. It seems we are hampered in reforming health care by our own historical affluence and by an unwillingness to take health insurance out of the free market - they are linked inextricably.

Although I am not an alarmist by nature, certainly a shift away from free market insurance to one gradually dominated by government would risk capricious wage and price controls, much like what happened when Philadelphia was conquered by the dominance of Independence Blue Cross and U.S. Healthcare Inc. in the early 1990s (9). If, for example, we pegged all provider reimbursements to current Medicare rates tomorrow, virtually every hospital in America would be under water, and, to restore solvency, all other costs for ancillary goods and services would have to fall, leaving various sectors of the human economy without jobs. On the face of it, this concern principally underlies general worry over government proposals to form a new public insurance program for the uninsured. It may not happen and government may just subsidize free market insurance plans with new tax revenue, but even this approach is not financially viable without voluntary or legislated cost containment.

The scale of this new tax burden could be partially offset by adjusting insurance copayments. Copayments are another way to bend the curve on incremental costs. The question is, can they be adapted to our cultural norms regarding unfettered access to health care. The Rand Health Insurance Experiment, now 25 years old, foretells that patients with health insurance seek more access unless copayments rise (10). Copayments are a form of cost sharing, and they do reduce clinical usage, but there is a wrinkle. Higher copayments cause some patients to forego medications, critical tests, or preventive care. This perversity can be minimized by value-based insurance design, where copayments are kept low for high-value health care services and raised for everything else (11); this strategy could be applied selectively across all insurance plans, perhaps adjusted for income or age, and probably deserves more attention.

Finally, the flurry of debate over health care reform neglects one other related point, and it is one of my favorites. Holly Smith once remarked that the continued existence of diseases for which we have no answers is the most pressing health care problem of our times. If health care were universally available tomorrow, even at no cost, people would still be sickened by many diseases from which they will die (12). More and better clinical science is fundamental to restoring health and lowering costs. Science, after all, is the only pathway to transforming technologies that are truly more affordable because they are decisive. Unfortunately, no one can easily absorb this latter message with all the dirt and twigs in the air.

\section{Eric G. Neilson}

Vanderbilt University School of Medicine, Nashville, Tennessee, USA. E-mail: eric. neilson@vanderbilt.edu.

J. Clin. Invest. 119:2849-2850 (2009). doi:10.1172/JCI40995.

1. Neilson, E.G. 2008. Baumol's curse on medicine. J. Am. Soc. Nephrol. 19:1049-1053.

2. Starr, P. 1982. The social transformation of American medicine. Basic Books. New York, New York, USA. 514 pp.

3. Hogan, C., Lunney, J., Gabel, J., and Lynn, J. 2001. Medicare beneficiaries' costs of care in the last year of life. Health Aff. (Millwood). 20:188-195.

4. Palangkaraya, A., and Yong, J. 2009. Population ageing and its implications on aggregate health care demand: empirical evidence from 22 OECD countries. Int. J. Health Care Finance Econ. Online publication ahead of print.

5. Ghosh, A.K. 2004. On the challenges of using evidence-based information: the role of clinical uncertainty. J. Lab. Clin. Med. 144:60-64.

6. Keckley, P.H. 2004. Evidence-based medicine in managed care: a survey of current and emerging strategies. MedGenMed. 6:56.

7. Peterson, C.L., and Burton, R. 2007. CRS report for Congress: U.S. health care spending: comparison with other OECD countries (RL34175). Congressional Research Service. Washington, DC. 65 pp.

8. Reid, T.R. 2009 August 23. 5 Myths about health care around the world. The Washington Post. http:// www.washingtonpost.com/wp-dyn/content/ article/2009/08/21/AR2009082101778.html.

9. Iglehart, J.K. 1995. Academic medical centers enter the market: the case of Philadelphia. N. Engl. J. Med. 333:1019-1023.

10. Manning, W.G., Leibowitz, A., Goldberg, G.A., Rogers, W.H., and Newhouse, J.P. 1984. A controlled trial of the effect of a prepaid group practice on use of services. N. Engl. J. Med. 310:1505-1510.

11. Chernew, M.E., and Newhouse, J.P. 2008. What does the RAND Health Insurance Experiment tell us about the impact of patient cost sharing on health outcomes? Am. J. Manag. Care. 14:412-414.

12. Smith, L.H., Jr. 1985. Alan Gregg memorial lecture. Medical education for the 21 st century. J. Med. Educ. 60:106-112.

\section{Health care reform: without a correct diagnosis, there is no cure}

\begin{abstract}
A persistent headache is a symptom, but the underlying cause can be anything from a migraine to a brain tumor. Good medicine means identifying and treating the cause as well as the symptom. The same is true in health care reform.
\end{abstract}

Though most Americans are satisfied with their own health care, they also see the need for substantial reform. Unfortunately, the well-meaning plans currently presented to Congress are the wrong therapy because they mistake the symptoms for the under- lying disease. Nearly everyone agrees on the symptoms: rapidly growing health expenditures, diminished access to affordable insurance causing many to be uninsured, and inadequate quality and outcomes for the dollars spent. But what are the root 